\section{Keeping Our Eyes on the Stars}

William F. Pridmore (MChD)

Royal Hobart Hospital

Hobart, Tasmania, Australia

Keywords: Motor neurone disease, humanities, hope.

The real problem is time.

She was finding it a bit harder to lift her foot. It was irritating, and she found she was limping. She made passing comments to her husband and son of some "electrical shocks" in her legs, which she thought were due to anxiety. That combination worried me, but I didn't tell her. It couldn't be.

A "foot drop" is a symptom in which the muscles that lift the toes towards the head lose this ability. There are many causes for such a presentation, and determining the culprit is challenging. Things didn't improve, and so she underwent a series of investigations. The neurologists who administered the nerve conduction studies were kind, but she noticed they exchanged serious looks throughout the test. She'd have to wait for the full report.

The full report was not good.

When the diagnosis of motor neurone disease is made in a family member, the world changes. It darkens around the edges, and loses some of its lustre. One can deal with the impending physical challenges as they arise. But it's the time that gets you. For most patients, lifespan is between two and five years from diagnosis. Nothing stops the march towards oblivion. We know how this story goes.

Massachusetts native Dr Stanley Appel is one of the rock stars of this condition. At 87 , he valiantly continues the research and clinical work he began as a young doctor. He calls MND “nice guys' disease", based on his observations that MND patients are typically driven, empathetic, generous, and otherwise healthy. Scientific studies, comparing patients with a healthy control population, confirm his notion ${ }^{1}$. MND patients are card-carrying nice guys - that's part of the injustice.

Research into MND has been frustratingly slow since the condition was first described by French neurologist Jean-Martin Charcot in the 1860s. Degeneration and death of motor neurones (nerve cells that control muscle movement) in the brain and spinal cord leads to progressive paralysis of voluntary muscles. The causes have remained elusive, and the biological processes that go astray are highly complex.

Most cases occur at random, but a minority run in families. When the first known genetic contributor was identified in the 1990s, it inspired the first animal model of MND, using laboratory mice. Such mouse models of MND have provided important insights about the injury of motor neurones, and have offered a useful way to test for the beneficial effects of various drugs. Unfortunately, these models have failed to bear much fruit. Contributing factors include poor experiment design, incompatibilities between mouse and human disease, and inadequate understanding to allow for informed therapeutic proposals ${ }^{2}$.

But something is shifting.

Decades of work by devoted researchers has discovered much of what leads to MND. There is more optimism than ever before. Slowly but steadily, scientists are developing a working knowledge of motor neurone death. In the same way MND insidiously takes over a body, research is progressively uncovering its secrets - and will eventually banish it. Several drugs and treatments show early promise.

2020 has seen the launch of three MND "platform trials": one in the UK, one in the USA, and one in Europe. Regularly used in cancer research, platform trials allow several drug candidates to be compared to a single placebo (fake drug) group at the same time. Contrasted with traditional clinical trials, platform trials may cut testing time in half, and expense by a third. The arrangement also means fewer patients who participate in trials will receive placebo. For a platform trial to be viable, there must be enough medications in development. For a drug company to develop a medication, it must know enough about a particular condition to identify a likely therapeutic target. Drug company interest in MND has increased out of sight over the last five years ${ }^{3}$.

University of Michigan linguist John M. Lawler offers the term "railroad time". It describes how, when science and technology is sufficiently advanced, it is natural for several people to make a discovery concurrently. Railroads were invented when it was "time for the railroads". I guess it is "railroad time" for MND platform trials.

Key discoveries hint that laboratory tests to reliably diagnose and monitor nerve damage may soon be available ${ }^{4}$. "Biomarkers" like these are desperately lacking. Implementation of such tests would revolutionise drug development, as researchers could tell quite quickly whether their medication was having an effect. 
What's On Your Mind?

The code is being cracked. You can hear the pins falling into place.

For now, we have learned to celebrate the small things, and seek joy. A new orthotic has stabilised her walking. Her arms are still strong - suddenly her love for kayaking is amplified. Her painting studio, always a special place, is now her salvation.

It is clear that MND is increasing in prevalence ${ }^{5}$. Despite its dramatic effects, the condition remains relatively underfunded. The Fight MND Foundation, championed by Australian Football League great Neale Daniher, has brought needed attention to our plight - and other excellent organisations around the world continue to raise funds.

More is needed, and needed quickly. Two Australians are diagnosed with, and die from, MND every day. The battle against this condition has felt like Sisyphus eternally pushing his boulder up a hill, only for it to roll back down when it nears the top. But now there is a difference. With renewed awareness and financial support, we may actually, finally, reach the summit.

And hopefully Mum will be standing with us, waving the flag of victory.

\section{Corresponding author}

William F. Pridmore

Royal Hobart Hospital, 48 Liverpool Street,

Hobart, Tasmania, Australia, 7000

Phone: +613 61668308

william.pridmore@ths.tas.gov.au

\section{References}

1. Parkin Kullmann JA, Hayes S, Pamphlett R. Are people with amyotrophic lateral sclerosis (ALS) particularly nice? An international online case-control study of the Big Five personality factors. Brain Behav 2018;8(10):e01119. DOI: 10.1002/brb3.1119

2. Petrov D, Mansfield C, Moussy A, Hermine O. ALS Clinical Trials Review: 20 Years of Failure. Are We Any Closer to Registering a New Treatment? Front Aging Neurosci 2017;9:68-68. DOI: 10.3389/fnagi.2017.00068

3. van Eijk RPA, Genge A. The rise of innovative clinical trial designs: what's in it for amyotrophic lateral sclerosis? Amyotroph Lateral Scler Frontotemporal Degener 2020;21(1-2):3-4. DOI: 10.1080/21678421.2019.1681455

4. Benatar M, Zhang L, Wang L, et al. Validation of serum neurofilaments as prognostic and potential pharmacodynamic biomarkers for ALS. Neurology 2020;95(1):e59-e69. DOI: 10.1212/ WNL.0000000000009559

5. Longinetti E, Fang F. Epidemiology of amyotrophic lateral sclerosis: an update of recent literature. Curr Opin Neurol 2019;32(5):771-776. DOI: 10.1097/ WCO.0000000000000730 